\title{
Prevalence and some of determinant factors of chronic kidney diseases among Saudi elderly in Arar, KSA
}

\author{
Ajaweed Saud Muharrab Alruwaili ${ }^{1}$, Amjad Saud Mhrb Alrowili ${ }^{2}$, Manal Nashi O Alshammari ${ }^{1}$, \\ Fahad Saad Salem Alanazi ${ }^{1}$, Nouf Saad Alanazi ${ }^{1}$, Mona Theyab Alanazi ${ }^{1}$, Reem Abdullaha Alanazi ${ }^{3}$, \\ Mubark Saleh Mubark Almarjan ${ }^{1}$, Mohammad Humood Meshref Alenezi ${ }^{1}$, Mohammed Sulaiman \\ Aljamal $^{4}$ \\ ${ }^{1}$ Faculty of Medicine, Northern Border University, $\mathrm{KSA},{ }^{2} \mathrm{PhD}$ clinical pharmacy, Northern Border University, \\ KSA, ${ }^{3}$ Faculty of Applied Medical Scinse, Northern Border University, KSA ${ }^{4}$ BPharm, MSc., PhD Clinical \\ Pharmacy, University of Manchester
}

\begin{abstract}
:
Background: Chronic kidney disease (CKD) is a global public health problem, affecting more than $10 \%$ of the world's population and more than half of adults older than 70years. It is one of several conditions that are common in older people, such as hypertension, diabetes, and hyperlipidemia, and are associated with an increased risk of cardiovascular disease. The aim of this study was to determine the prevalence and some of determinant factors of chronic kidney diseases among Saudi elderly in Arar, KSA. Methods: The present cross sectional community based study was conducted in Arar city, the capital of Northern Borders Governorate on 276 participants, of age 60 years and more. Systematic random sampling technique was followed. Data was collected through personal interviews with the sampled population and filling the questionnaire which guided us to the data of sociodemographic characteristics such as age, sex, educational status and marital status, it also included smoking status and certain types of diseases that may be prevalent among elderly suggested affecting renal diseases such as hypertension, diabetes millets and obesity. Results: The majority of the participants was females $(55.2 \%)$, had mean age $( \pm \mathrm{SD})$ of $60( \pm 9.25)$ years, $6.5 \%$ had renal insufficiency, $5.8 \%$ diabetic nephropathy, $1.4 \%$ chronic kidney failures. Only $3.2 \%$ had both hypertension and kidney resection, 3.2\% hypertension with diabetic nephropathy and $6.3 \%$ had hypertension and renal insufficiency, $13.7 \%$ had diabetes with diabetic nephropathy, $3.9 \%$ had diabetes with chronic kidney failure and $7.8 \%$ had both diabetes and renal insufficiency. $3.2 \%$ were obese and had kidney resection, $6.3 \%$ obese with diabetic nephropathy, and $3.2 \%$ obese with chronic kidney failure and $4.8 \%$ obese with renal insufficiency. Conclusion: Chronic kidney diseases are common in older people in Arar city, Northern Saudi Arabia. 6.5\% had renal insufficiency, 5.8\% had diabetic nephropathy, $1.4 \%$ had chronic kidney failures and 1.4\% had Kidney resection. Large scale community based studies with detailed investigations are needed. Health education directed to elderly population and their care givers about renal diseases and its risk factors are mandatory.
\end{abstract}

Key words: Prevalence, determinants, factors, chronic kidney diseases, Saudi elderly, Arar, KSA

\section{Introduction:}

Chronic kidney disease is a very common clinical problem in elderly patients and is associated with increased morbidity and mortality ${ }^{[1]}$. It is defined as an abnormality in renal structure or function which is present for a period of three months or longer and has resultant implications for health, with glomerular filtration rate (GFR) and albuminuria being used to define the stages of the illness ${ }^{[2]}$. Chronic kidney disease is one of several conditions that are common in older people, such as hypertension, diabetes, and hyperlipidemia, and are associated with an increased risk of cardiovascular disease ${ }^{[3]}$. Although considerable interest continues to mount on diseases of the elderly, there is no 
universally accepted definition of elderly particularly in patients with chronic kidney disease ${ }^{[4]}$. Regarding rapid increase in the elderly population, the epidemiology and pathophysiology of CKD in these individuals are noteworthy. Based on a 10 year study on , it has been shown that the incidence of ESRD in patients older than 65 years have increased from $16.4 \%$ in 1996 to more than $29 \%$ in 2005 and $2006^{[5]}$. This is attributable mainly to increasing prevalence of traditional risk factors for CKD such as diabetes, ${ }^{[6]}$ hypertension and cardiovascular disease (CVD) as well as due to new definitions that have expanded the estimated glomerular filtration rate range for CKD. CKD is diagnosed in healthy elderly subjects whose renal function is below the normal range. However, it is difficult to know the anatomy of the kidney change with natural aging in the absence of CKD ${ }^{[7]}$. There is limited information for evidence-based guidelines and recommendations for managing CKD in the elderly. Geriatric issues such as frailty, quality of life, life expectancy, end of life issues, pharmacokinetics and pharmacodynamics of drugs and treatment complications must be addressed when planning the management of CKD in the elderly ${ }^{[8]}$.

A study was carried out in Hail region in KSA by Ginawi et al. ${ }^{[9]}$ found that CKD was identified in 70/299 (24\%), of whom $27 / 70$ $(38.6 \%)$ were males and $43 / 70(61.4 \%)$ were females, $49 / 70(70 \%, \mathrm{P}=0.001)$ were cases of diabetes, while $45 / 70(64.3 \%, \mathrm{P}=0.001)$ were with hypertension.

The main aim of this study was to determine the prevalence and some of determinant factors of chronic kidney diseases among Saudi elderly in Arar, KSA

\section{Participants and methods:}

The present cross sectional community based study was conducted in Arar city, the capital of Northern Borders Governorate on 276 participants, of age 60 years and more. The sample size was calculated using the sample size equation: $n=z^{2} p \quad(1-p) / e^{2}$, considering target population more than 1000 , and study power $95 \%$. Systematic random sampling technique was followed. After identifying the first house randomly in the selected area, every $9^{\text {th }}$ house was visited to include all the adult subjects residing in those selected houses till the required sample is covered. Data were collected through personal interviews with the sampled population and filling the questionnaire which guided us to the data of the socio-demographic characteristics such as age, sex, educational status and marital status, it also included smoking status and certain types of diseases that may be prevalent among elderly suggested affecting the kidney such as hypertension, diabetes millets and obesity. The questionnaire included also questions regarding the already previously diagnosed chronic kidney diseases and its determinants, after ensuring the diagnosis by reviewing the accompanied health records and prescriptions and asking the caregivers about the case.

\section{Ethical considerations}

Data collector gave a brief introduction to the participants by explaining the aims and benefits of the study. Informed written consent was obtained from all participants. Anonymity and confidentiality of data were maintained throughout the study. There was no conflict of interest.

\section{Results:}

Table (1) shows the socio-demographic characteristics of the participants, Northern Border Saudi Arabia. The majority of the participants were females (55.2\%), had mean age $( \pm \mathrm{SD})$ of $60( \pm 9.25)$ years, $62.3 \%$ were married and $48.6 \%$ were illiterate. About $7.2 \%$ of them were smokers.

As viewed in table (2); $6.5 \%$ of studied population had renal insufficiency, $5.8 \%$ diabetic nephropathy, $1.4 \%$ for chronic kidney failure. $44.9 \%$ of studied sample had 
Prevalence and some of determinant factors of chronic kidney diseases...

hypertension, $\quad 37 \% \quad \mathrm{DM}, \quad 47.8 \%$ hyperlipidemia, $17.4 \%$ thyroid diseases (hyper and hypo) while $26.8 \%$ were overweight.

Regarding chronic diseases as presented in table 4, 5 and 6; 3.2\% had both hypertension and kidney resection, $3.2 \%$ hypertension with diabetic nephropathy and $6.3 \%$ had hypertension and renal insufficiency. No cases had kidney resection and diabetes, $13.7 \%$ had diabetes with diabetic nephropathy, 3.9\% had diabetes with chronic kidney failure and $7.8 \%$ had both diabetes and renal insufficiency. $3.2 \%$ were obese and had kidney resection, $6.3 \%$ obese with diabetic nephropathy, $3.2 \%$ obese with chronic kidney failure and $4.8 \%$ obese with renal insufficiency

Table (1): Socio-demographic characteristics and smoking among the studied elderly, Arar, 2017 ( $N=276)$

\begin{tabular}{|c|c|c|}
\hline Variables & $\begin{array}{c}\text { Frequency } \\
\text { (No.) }\end{array}$ & Percent (\%) \\
\hline \multicolumn{3}{|l|}{ Age group } \\
\hline - $60-$ & 180 & 65.2 \\
\hline - $70-$ & 72 & 26.1 \\
\hline - $80+$ & 24 & 8.7 \\
\hline - $\quad$ Mean age $( \pm$ SD $)$ & \multicolumn{2}{|c|}{$60 \pm 9.25$} \\
\hline \multicolumn{3}{|l|}{ Sex } \\
\hline - Female & 144 & 52.2 \\
\hline - Male & 132 & 47.8 \\
\hline \multicolumn{3}{|l|}{ Education } \\
\hline - Illiterate & 134 & 48.6 \\
\hline - Primary & 54 & 19.6 \\
\hline - Preparatory & 22 & 8.0 \\
\hline - Secondary & 22 & 8.0 \\
\hline - University or more & 44 & 15.9 \\
\hline \multicolumn{3}{|l|}{ Working status } \\
\hline - $\quad$ Shepherd & 30 & 10.9 \\
\hline - $\quad$ Military & 6 & 2.2 \\
\hline - No work & 148 & 53.6 \\
\hline - $\quad$ Retired & 92 & 33.3 \\
\hline \multicolumn{3}{|l|}{ Marital status } \\
\hline - Widow & 92 & 33.3 \\
\hline - Single & 6 & 2.2 \\
\hline - Married & 172 & 62.3 \\
\hline - Divorced & 6 & 2.2 \\
\hline \multicolumn{3}{|l|}{ Smoking } \\
\hline - Non smoker & 186 & 68.8 \\
\hline - Smokers & 20 & 7.2 \\
\hline - Ex-Smoker & 66 & 23.9 \\
\hline
\end{tabular}


Figure (1): Chronic kidney diseases among the studied elderly population, Arar, 2017

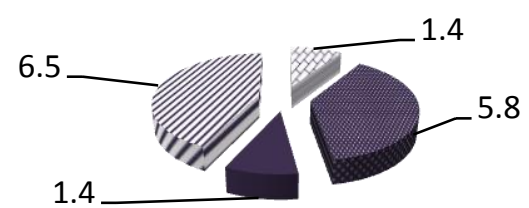

\section{y. Kidney resection $\quad$ : Diabetic nephropathy}

Table (2): Prevalence of chronic kidney diseases and other related chronic diseases among the studied population, Arar, 2017 (N=276)

\begin{tabular}{|c|c|c|}
\hline Chronic kidney diseases & No. & $\%$ \\
\hline - Kidney resection & 4 & 1.4 \\
\hline - Diabetic nephropathy & 16 & 5.8 \\
\hline - Chronic kidney failure. & 4 & 1.4 \\
\hline - Renal insufficiency & 18 & 6.5 \\
\hline - No chronic kidney disease & 234 & 84.8 \\
\hline \multicolumn{3}{|l|}{ Hypertension } \\
\hline - Yes & 124 & 44.9 \\
\hline - $\mathrm{No}$ & 152 & 55.1 \\
\hline \multicolumn{3}{|l|}{ Diabetes } \\
\hline - Yes & 102 & 37.0 \\
\hline - $\mathrm{No}$ & 174 & 63.0 \\
\hline \multicolumn{3}{|l|}{ Body Mass Index $(\mathrm{kg} / \mathrm{m} 2)$ status } \\
\hline - Underweight & 8 & 2.9 \\
\hline - Normal & 68 & 24.6 \\
\hline - Overweight & 74 & 26.8 \\
\hline - Obese & 126 & 45.7 \\
\hline Mean BMI ( \pm SD) & \multicolumn{2}{|c|}{$29.99 \pm 9.73$} \\
\hline \multicolumn{3}{|l|}{ Hyperlipidemia } \\
\hline - Yes & 132 & 47.8 \\
\hline - No & 144 & 52.2 \\
\hline \multicolumn{3}{|l|}{ Thyroid diseases } \\
\hline - Hyperthyroidism & 14 & 5.1 \\
\hline - Hypothyroidism & 34 & 12.3 \\
\hline - $\mathrm{No}$ & 228 & 82.6 \\
\hline
\end{tabular}


Table (3): Chronic kidney diseases and gender among the studied elderly, Arar, 2017

\begin{tabular}{|c|c|c|c|}
\hline \multirow[t]{2}{*}{ Chronic kidney diseases } & \multicolumn{2}{|c|}{ Gender } & \multirow[t]{2}{*}{ Total $(n=276)$} \\
\hline & No $(n=144)$ & Yes $(n=132)$ & \\
\hline \multirow[t]{2}{*}{ - Kidney resection } & 4 & $\mathbf{0}$ & 4 \\
\hline & $2.8 \%$ & $.0 \%$ & $1.4 \%$ \\
\hline \multirow[t]{2}{*}{ - Diabetic nephropathy } & 4 & 12 & 16 \\
\hline & $2.8 \%$ & $9.1 \%$ & $5.8 \%$ \\
\hline \multirow[t]{2}{*}{ - Chronic kidney failure. } & 4 & $\mathbf{0}$ & 4 \\
\hline & $2.8 \%$ & $.0 \%$ & $1.4 \%$ \\
\hline \multirow[t]{2}{*}{ - Renal insufficiency } & 2 & 16 & 18 \\
\hline & $1.4 \%$ & $12.1 \%$ & $6.5 \%$ \\
\hline \multirow{2}{*}{$\begin{array}{l}\text { No chronic kidney } \\
\text { disease }\end{array}$} & 130 & 104 & 234 \\
\hline & $90.3 \%$ & $\mathbf{7 8 . 8 \%}$ & $84.8 \%$ \\
\hline
\end{tabular}

Table (4): Chronic kidney diseases and hypertension among the studied elderly, Arar, 2017

\begin{tabular}{|c|c|c|c|}
\hline \multirow{2}{*}{ Chronic kidney diseases } & \multicolumn{2}{|c|}{ Hypertension } & \multirow{2}{*}{ Total (n=276) } \\
\cline { 2 - 4 } & No $(\mathbf{n = 1 5 0})$ & Yes $(\mathbf{n = 1 2 6})$ & \\
\hline \multirow{2}{*}{ Kidney resection } & $\mathbf{0}$ & 4 & 4 \\
\cline { 2 - 4 } & $\mathbf{. 0 \%}$ & $\mathbf{3 . 2 \%}$ & $\mathbf{1 . 4 \%}$ \\
\hline \multirow{2}{*}{ Diabetic nephropathy } & 12 & 4 & 16 \\
\cline { 2 - 4 } & $\mathbf{8 . 0 \%}$ & $\mathbf{3 . 2 \%}$ & $\mathbf{5 . 8 \%}$ \\
\hline \multirow{2}{*}{ Chronic kidney failure. } & 4 & $\mathbf{0}$ & 4 \\
\cline { 2 - 4 } & $\mathbf{2 . 7 \%}$ & $\mathbf{0 \%}$ & $\mathbf{1 . 4 \%}$ \\
\hline \multirow{2}{*}{ Renal insufficiency } & $\mathbf{1 0}$ & $\mathbf{8}$ & $\mathbf{1 8}$ \\
\cline { 2 - 4 } & $\mathbf{6 . 7 \%}$ & $\mathbf{6 . 3 \%}$ & $\mathbf{6 . 5 \%}$ \\
\hline \multirow{2}{*}{$\begin{array}{l}\text { No chronic kidney } \\
\text { disease }\end{array}$} & $\mathbf{1 2 4}$ & $\mathbf{1 1 0}$ & $\mathbf{2 3 4}$ \\
\cline { 2 - 4 } & $\mathbf{8 2 . 7 \%}$ & $\mathbf{8 7 . 3 \%}$ & $\mathbf{8 4 . 8 \%}$ \\
\hline
\end{tabular}

Table (5): Chronic kidney diseases and diabetes among the studied elderly, Arar, 2017

\begin{tabular}{|c|c|c|c|}
\hline \multirow[t]{2}{*}{ Chronic kidney diseases } & \multicolumn{2}{|c|}{ Diabetes } & \multirow[t]{2}{*}{ Total $(n=276)$} \\
\hline & Yes $(n=51)$ & No $(n=174)$ & \\
\hline \multirow{2}{*}{ - Kidney resection } & o & 4 & 4 \\
\hline & $.0 \%$ & $2.3 \%$ & $1.4 \%$ \\
\hline \multirow[t]{2}{*}{ - Diabetic nephropathy } & 7 & 2 & 16 \\
\hline & $13.7 \%$ & $1.1 \%$ & $5.8 \%$ \\
\hline \multirow[t]{2}{*}{ - Chronic kidney failure. } & 2 & $\mathbf{0}$ & 4 \\
\hline & $3.9 \%$ & $.0 \%$ & $1.4 \%$ \\
\hline \multirow[t]{2}{*}{ - Renal insufficiency } & 4 & 10 & 18 \\
\hline & $7.8 \%$ & $5.7 \%$ & $6.5 \%$ \\
\hline \multirow{2}{*}{$\begin{array}{l}\text { - No chronic kidney } \\
\text { disease }\end{array}$} & 38 & 158 & 234 \\
\hline & $74.5 \%$ & $90.8 \%$ & $84.8 \%$ \\
\hline
\end{tabular}


Ajaweed Alruwaili et al.

Table (6): Chronic kidney diseases and BMI among the studied elderly, Arar, 2017

\begin{tabular}{|c|c|c|c|c|c|}
\hline \multirow{2}{*}{$\begin{array}{l}\text { Chronic kidney } \\
\text { diseases }\end{array}$} & \multicolumn{4}{|c|}{ BMI group } & \multirow{2}{*}{$\begin{array}{c}\text { Total } \\
(\mathbf{n}=276)\end{array}$} \\
\hline & $\begin{array}{c}\text { Underweight } \\
\qquad(\mathbf{n}=\mathbf{8})\end{array}$ & $\begin{array}{c}\text { Normal } \\
(n=68)\end{array}$ & $\begin{array}{c}\text { Overweight } \\
(n=74)\end{array}$ & $\begin{array}{c}\text { Obese } \\
(n=126)\end{array}$ & \\
\hline \multirow{2}{*}{$\begin{array}{ll}- & \text { Kidney } \\
& \text { resection } \\
\end{array}$} & 0 & 0 & $\mathbf{0}$ & 4 & 4 \\
\hline & $.0 \%$ & $.0 \%$ & $.0 \%$ & $3.2 \%$ & $1.4 \%$ \\
\hline \multirow{2}{*}{$\begin{array}{ll}\text { - } & \text { Diabetic } \\
\text { nephropathy }\end{array}$} & 0 & 4 & 4 & 8 & 16 \\
\hline & $.0 \%$ & $5.9 \%$ & $5.4 \%$ & $6.3 \%$ & $5.8 \%$ \\
\hline \multirow{2}{*}{$\begin{array}{l}\text { Chronic } \\
\text { kidney } \\
\text { failure. }\end{array}$} & $\mathbf{0}$ & 0 & 0 & 4 & 4 \\
\hline & $.0 \%$ & $.0 \%$ & $.0 \%$ & $3.2 \%$ & $1.4 \%$ \\
\hline \multirow{2}{*}{$\begin{array}{ll}\text { - } & \text { Renal } \\
\text { insufficiency }\end{array}$} & 0 & 8 & 4 & 6 & 18 \\
\hline & $.0 \%$ & $11.8 \%$ & $5.4 \%$ & $4.8 \%$ & $6.5 \%$ \\
\hline \multirow{2}{*}{$\begin{array}{ll}\text { No chronic } \\
\text { kidney } \\
\text { disease }\end{array}$} & 8 & 56 & 66 & 104 & 234 \\
\hline & $100.0 \%$ & $82.4 \%$ & $89.2 \%$ & $82.5 \%$ & $84.8 \%$ \\
\hline
\end{tabular}

\section{Discussion}

Chronic kidney disease (CKD) is considered an important public health problem ${ }^{[10]}$, as it increases the mortality risk for any cause, which increases the frequency of cardiovascular disease episodes and the progression to end-stage renal disease (ESRD) independently of traditional CVRF ${ }^{[11,12,13,14]}$. According to this guideline, $\mathrm{CKD}$ is defined as either kidney damage or glomerular filtration rate (GFR) below $60 \mathrm{ml} / \mathrm{min} / 1.73 \mathrm{~m} 2$ for three or more months with or without evidence of kidney damage, irrespective of the cause ${ }^{[15]}$. This is cross sectional community based study was conducted in Arar city, the capital of Northern Borders Governorate on 276 elderly people of age 60 years and more .The study aimed to determine the prevalence and some of determinant factors of chronic kidney diseases among Saudi elderly in Arar, KSA. According to prevalence of chronic kidney diseases, our study found that; the prevalence of renal insufficiency was $6.5 \%$, diabetic nephropathy $5.8 \%$, kidney resection and chronic kidney failure $1.4 \%$.In Riyadh, the capital of the kingdom of Saudi Arabia, a study conducted among 491 adult Saudi nationals; the overall CKD prevalence of all stages was 5.7\% and 5.3\% using the MDRD-3 and CKD-EPI glomerular filtration equations, respectively, the prevalence of CKD stages 1 , 2 and 3 was $3.5 \%, 1.6 \%$ and $0.6 \%$, respectively ${ }^{[16]}$. In Beijing, China a crosssectional study conducted among 13,925 adults reported the prevalence of CKD was $13.0 \%{ }^{[17]}$. In USA, the prevalence rate over 1999-2004 was $13.1 \%$ in all four stages of CKD $(1.8 \%, 3.2 \%, 7.7 \%$ and $0.35 \%$ for stages $1,2,3$ and 4 , respectively) ${ }^{[18]}$. A population of American Indians and Alaska Natives was screened for CKD as part of the Kidney Early Evaluation Program (KEEP); in this population, the prevalence of any CKD was found to be $29 \%$ and of low GFR (defined as $<60 \mathrm{~mL} / \mathrm{min} / 1.73 \mathrm{~m} 2$ ) was $17 \%{ }^{[19]}$. In Jing adults in China another study carried out among 757 Jing adults, overall CKD prevalence was $15.3 \%{ }^{[20]}$. A primary carebased cross-sectional study was conducted in Taian, China; of the 14,399 subjects, 1,366 (9.49\%) were positive for CKD ${ }^{[21]}$. In Hail region, KSA a cross sectional survey that included data from 299 Saudis from general population 70/299 (24\%) were found with different stages of CKD of the 70 cases of CKD, stage III, stage II and stage I were identified in $5 / 70(7.14 \%), 21 / 70(30 \%)$ and $44 / 70(62.86 \%)$, respectively ${ }^{[9]}$. In another study, the overall prevalence of CKD in Norway was $10.2 \%{ }^{[22]}$. Another study was conducted to estimate the overall prevalence of stages of chronic kidney disease in Hail Region, KSA among 2,946 individuals, 
278/2946 (9.4\%) were found with CKD ${ }^{[9]}$. Another study reported that prevalence of CKD in the US adult population was $11 \%$ and the prevalence in the US elderly was much higher at about $39.4 \%$ of persons aged $60+$ years have been noted to have CKD versus 12.6 and $8.5 \%$ of persons aged $40-59$ years and 20-39 years, respectively ${ }^{[24]}$. Based on studies conducted in different countries, the prevalence of CKD varies from $6.5 \%$ in a study in Iran to $33 \%$ in Mexico ${ }^{[24,25]}$. In West Malaysia the overall prevalence of CKD was 9.07\% ${ }^{[26]}$. The prevalence of CKD in Asia varies from $6.8 \%$ in South Korea, $12 \%$ in Taiwan and $13 \%$ in Japan to $17.5 \%$ in Thailand ${ }^{[27]}$.

Our study reported other related chronic diseases among studied populations; hypertension $44.9 \%$, diabetes $37 \%$, hyperlipidemia $47.8 \%$, obese $45.7 \%$ and overweight $26.8 \%$. Another study reported in chronic diseases cases, the prevalence of hypertension, diabetes, hyperlipidemia and hyperuricemia was $14.8 \%, 5.2 \%, 38 \%$ and $16.2 \%$, respectively, Prevalence of overweight or obesity status and metabolic syndrome was $12.1 \%$ and $3.0 \%{ }^{[20]}$. Another study reported high levels of CKD risk factors were identified in varying proportion among the study population. Systolic blood pressure (BP), diastolic BP, DM, creatinine, urea, and uric acid were identified in (37\%), (26.4\%), (26\%), $(5 \%),(8 \%)$ and $(4 \%)$, respectively ${ }^{[9]}$.

As regards the association between risk factors for CKD and CKD, our study reported that hypertension was identified among 4 (3.2\%), $4(3.2 \%)$ and $8(6.3 \%)$ of those with kidney resection, diabetic nephropathy and renal insufficiency respectively. DM was identified among 7(13.7\%) with diabetic nephropathy, $2(3.9 \%)$ with chronic kidney failure and 4(7.8\%) with renal insufficiency. In Hail region, KSA Another study reported that hypertension was identified among 4 (80\%), $14(67 \%)$ and $13(30 \%)$ of those with stages 1$4 \mathrm{CKD}$, respectively $(\mathrm{P}<0.00001)$. $\mathrm{DM}$ was identified among 3(60\%), $14(67 \%)$ and 15 $(36 \%)$ of those with stages 1- 4 CKD, respectively $\quad(\mathrm{P}<0.00001)$. Stroke was identified among 2 (40\%), 3 (14\%) and 2 $(4.5 \%)$ of those with stages 1- 4 CKD, respectively $(\mathrm{P}<0.00001)$. Ischemic heart attack was experienced among 1 (20\%), 6
(28\%) and $4(9 \%)$ of those with stages 1- 4 CKD, respectively $(\mathrm{P}<0.00001)$. CHF was found among 1 (20\%), 2 (10\%) and 1 (2.3\%) of those with stages 1- $4 \mathrm{CKD}$, respectively $(\mathrm{P}<0.002)$. Recurrent Urinary tract infection (UTI) was found among 1 (20\%), 8 (38\%) and 26 (59\%) of those with stages 1- 4 CKD, respectively $(\mathrm{P}<0.004)^{[9]}$.

\section{Conclusion and recommendations:}

Chronic kidney diseases are common in older people in Arar city, Northern Saudi Arabia. $6.5 \%$ had renal insufficiency, 5.8\% had diabetic nephropathy, $1.4 \%$ had chronic kidney failures and $1.4 \%$ had Kidney resection. Large scale community based studies with detailed investigations are needed. Health education directed to elderly population and their care givers about renal diseases and its risk factors are mandatory.

\section{References:}

1. McClure M, Jorna T, Wilkinson $\mathbf{L}$ et al. (2017): Joanne Taylor; Elderly patients with chronic kidney disease: do they really need referral to the nephrology clinic?, Clinical Kidney Journal, 10(5):698-702.

2. Kidney Disease: Improving Global Outcomes (KDIGO) CKD Work Group (2013): KDIGO 2012 Clinical Practice Guideline for the Evaluation and Management of Chronic Kidney Disease. Kidney Int.,3(1):1-150.

3. Levey AS, Inker LA, Coresh J (2015): Chronic Kidney Disease in Older People. JAMA. 314(6):557558. doi:10.1001/jama.2015.6753

4. Mallappallil M, Friedman EA, Delano BG et al. (2014): Chronic kidney disease in the elderly: evaluation and management. Clinical practice (London, England),11(5):525-535.

5. Aghighi M, Mahdavi-Mazdeh M, Zamyadi M et al. (2009): Changing epidemiology of end-stage renal disease in last 10 years in Iran. Iran $\mathbf{J}$ Kidney Dis.,3(4): 192-6 
6. Williams M (2013): Diabetic kidney disease in elderly individuals. Med Clin North Am., 97(1):75-89.

7. Anderson S, Halter JB, Hazzard WR et al. (2009): Prediction, progression, and outcomes of chronic kidney disease in older adults. J Am Soc Nephrol.,20:1199-1209.

8. Fassett RG (2014): Current and emerging treatment options for the elderly patient with chronic kidney disease. Clin Interv Aging,15(9):191199.

9. Ginawi IA, Elasbali AM, Ahmed et al. (2013): Population screening for chronic kidney disease and its associated risk factors: a survey in Hail region, KSA. J. Public Health Epidemiol., 5(7): 285-290.

10. Levey AS, Atkins R, Coresh J et al. (2007): Chronic kidney disease as a global public health problem: approaches and initiatives - a position statement from kidney disease improving global outcomes. Kidney Int., 72: 247-259.

11. Sarnak MJ, Levey AS, Schoolwerth AC et al. (2003): Kidney disease as a risk factor for development of cardiovascular disease: a statement from the American heart association councils on kidney in cardiovascular disease, high blood pressure research, clinical cardiology, and epidemiology and prevention. Circulation, 108: 2154-2169.

12. Go AS, Chertow GM, Fan D et al. (2004): Chronic kidney disease and the risks of death, cardiovascular events, and hospitalization. N Engl J Med., 351: 1296-1305.

13. Schiffrin EL, Lipman ML, Mann JF (2007): Chronic kidney disease: effects on the cardiovascular system. Circulation., 116: 85-97.

14. Matsushita $K$, van der Velde $M$, Astor BC et al. (2010): Association of estimated glomerular filtration rate and albuminuria with all-cause and cardiovascular mortality in general population cohorts: a collaborative meta-analysis. Lancet, 375: 20732081.

15. Levey AS, Coresh J, Balk E et al. (2003): National Kidney Foundation practice guidelines for chronic kidney disease: evaluation, classification, and stratification. Ann Intern Med.,139:137-147.

16. Alsuwaida AO, Farag YM, Al Sayyari AA et al. (2010): Epidemiology of chronic kidney disease in the Kingdom of Saudi Arabia (SEEK-Saudi investigators) A pilot study. Saudi J Kidney Dis Transpl., 21:1066-72.

17. Zhang L, Zhang $P$, Wang $F$ et al. (2008): Prevalence and factors associated with CKD: A population study from Beijing. Am J Kidney Dis., 51:373-84.

18. Coresh J, Selvin E, Stevens LA et al. (2007): Preva-lence of chronic kidney disease in the United States. JAMA., 298(17):2038-47.

19. Jolly SE, Li S, Chen SC et al. (2008): Risk Factors for Chronic Kidney Disease among American Indians and Alaska Natives - Findings from the Kidney Early Evaluation Program. Am J Nephrol.,29(5):440-6.

20. Xue C, Ye XD, Li W et al. (2013): Prevalence of chronic kidney disease in Jing adults in China: a village-based study. Clin Nephrol.,79(1):50-6.

21. Xue L, LouY, Feng X et al. (2014): Prevalence of chronic kidney disease and associated factors among the Chinese population in Taian, China. BMC Nephrology, 15:205.

22. Hallan SI, Coresh J, Astor BC et al. (2016): International comparison of the relationship of chronic kidney disease prevalence and ESRD risk. J. Am. Soc. Nephrol., 17:2275.

23. Coresh J, Astor B, Greene T et al. (2003): Prevalence of chronic kidney disease and decreased kidney function in the adult US population: Third National Health and Nutrition Examination Survey. Am J Kidney Dis.,41: 1-12.

24. Obrador GT, Mahdavi-Mazdeh M, Collins AJ (2011): Global Kidney Disease Prevention N. Establishing the Global Kidney Disease Prevention 
Network (KDPN): a position statement from the National Kidney Foundation. Am J Kidney Dis.,57(3): 361-70.

25. Hwang SJ, Lin MY, Chen HC et al. (2008): Increased risk of mortality in the elderly population with late-stage chronic kidney disease: a cohort study in Taiwan. Nephrol Dial Transplant.,23(10): 3192-8.

26. Hooi LS, Ong LM, Ahmad G et al. (2013): A population-based study measuring the prevalence of chronic kidney disease among adultsin West Malaysia Kidney International, 84, 1034-1040.

27. Li PKT, Chow KM, Matsuo S et al. (2011): Asian chronic kidney disease (CKD) best practice recommendations: positional statements for early detection of CKD from Asian Forum for CKD Initiatives (AFCKDI). Nephrology (Carlton), 16: 633-641. 